\title{
Environmental rugosity, body size and access to food: a test of the size-grain hypothesis in tropical litter ants
}

\author{
Alejandro G. Farii-Brener, Gilbert Barrantes and Adriana Ruggiero
}

Farji-Brener, A. G., Barrantes, G. and Ruggiero, A. 2004. Environmental rugosity, body size and access to food: a test of the size-grain hypothesis in tropical litter ants. - Oikos 104: 165-171.

\begin{abstract}
In terrestrial walking organisms, long legs help to decrease the cost of running, allowing animals to step over environmental interstices rather than walking through them. However, long legs can complicate the infiltration of these interstices, which may contain food sources and refugia. Since the number of environmental interstices perceived by an organism (rugosity) increases as it body size decreases (size-grain hypothesis, SGH), natural selection should favor proportionally smaller legs with decreasing body size. Recent work demonstrated that ants fit this hypothesis. We experimentally tested the assumption of the SGH that small ants, which have proportionally smaller legs than larger ants, are more successful in exploring environmental interstices because they can easily penetrate them. We examined the ability of tropical litter ant species with different body sizes to access food baits in 'landscapes' (= plots) with different levels of rugosity and food exposure. In the first experiment, three levels of landscape rugosity were defined by manipulating the density of leaf litter placed on the ground plots: a) plain landscape: no litter fall, b) intermediate rugosity $(\sim 0.5 \mathrm{~kg}$ of litter fall) and c) high rugosity $(\sim 1 \mathrm{~kg})$. In a second experiment, food baits were in plain landscapes, exposed or covered by leaf litter. The body lengths of ants that first accessed food baits ranged from 1.5 to $12 \mathrm{~mm}$. Ants that first reached food baits in the most rugose landscapes were $\sim 40 \%$ smaller than ants that first found baits in plain landscapes. Smaller ants were also the first to access covered food. The application of a phylogenetic comparative method suggested the same patterns. We conclude that these results support the size grain hypothesis. Environmental rugosity might have operated as a selective force to shape the morphological characteristics of litter ant species.
\end{abstract}

A. G. Farji-Brener and A. Ruggiero, Lab. Ecotono, Depto. de Ecología, CRUB, Univ. del Comahue, 8400 Bariloche, Argentina (alefarji@crub.uncoma.edu.ar). - G. Barrantes, Escuela de Biología, Univ. de Costa Rica, San José, Costa Rica.

Ecologists have long recognized the influence of landscape heterogeneity and body size on animal performance separately (Peters 1983, Wiens 1989, Wainwright 1996). For example, several works have shown that the grain of heterogeneity (or scale of patchiness, Sparow 1999) affects foraging behavior (Crist and Wiens 1994, Schmidt and Brown 1996) and the pattern of animal movement (Gross et al. 1995, Wiens et al. 1997, McIntyre and Wiens 1999, Morales 2002). On the other hand, both intra- and interspecific differences in body size have long been considered central to niche segrega- tion (Hutchinson 1959, Brown 1975), influencing, for instance, the range of food that an animal can exploit efficiently (Lindstrom et al. 1994). However, the effect of environmental heterogeneity on the performance of an organism is determined in part by the level of heterogeneity at which it perceives the environment, which in turn depends on body size (Levin 1992, Irschick and Garland 2001).

It has been proposed that the environmental rugosity (e.g. the number of environmental interstices) perceived by terrestrial walking organisms is bigger for small

Accepted 21 June 2003

Copyright (C) OIKOS 2004

ISSN 0030-1299

OIKOS 104:1 (2004) 
individuals than for large individuals (size-grain hypothesis, Kaspari and Weiser 1999). This hypothesis (hereafter $\mathrm{SGH}$ ) proposes that the allometric relationship between the two main parts of the fundamental body plan of walking animals (i.e., ventral legs protuding from a longitudinal body axis) determines the organism's ability to move within a particular landscape (Kaspari and Weiser 1999, Irschick and Garland 2001). Longer legs in large organisms decrease the cost of running and allow animals to walk over environmental interstices instead of walking into them. However, long legs can complicate the organisms' ability to infiltrate interstices, which may contain food sources and refugia. Because the perception of environmental rugosity increases as body size decreases (SGH), Kaspari and Weiser (1999) propose that the benefits of long legs are outweighed by the costs of leg construction in small animals, and thus natural selection should favor proportionately smaller legs with decreasing body size. As a consequence, given similar behaviors, small animals walk into the landscape, mid-size animals walk around it, and large animals walk over it (Kaspari and Weiser 1999). The SGH predicts that small ants will have proportionally smaller legs than larger ants and thus be more successful in exploring environmental interstices. Two recent works have demonstrated that leg length decreases disproportionately to body size in 142 ant species belonging to 5 sub-families (Kaspari and Weiser 1999, Espadaler and Gómez 2001); however, the functional relationship between this allometric pattern and habitat perception has not yet been explicitly tested. In the present paper we use tropical litter ants as a model system to experimentally test whether body size and leg length of ants affect their ability to explore resources in natural interstices in landscapes with different levels of rugosity (as defined below). We focused on tropical litter ants because: (1) they are common and diverse, showing large interspecific variation in body size, (2) their habitat is naturally complex, as leaves, twigs, and other debris are common components in their landscape, and (3) food resource availability may be directly related to landscape rugosity in ants, since food items from different sources are commonly present in these interstices (Hölldobler and Wilson 1990, Tobin 1994).

The variation in leaf litter density and its spatial distribution on the forest floor determine different kinds of environmental heterogeneity ( = environmental rugosity) that can potentially affect the performance of litter ants. For example, a food item (e.g. a larva) may be exposed on, or covered by, a pile of dead leaves which, in turn, at a larger scale (i.e. of $\mathrm{m}^{2}$ ) may be surrounded by a plain (with no litter fall) or rugose (with litter fall) landscape. In the present paper, we experimentally modified the levels of landscape rugosity and food exposure to examine the effect of such variables on the ability of ants with different body sizes to find and use food resources hidden in environmental interstices. According to the size-grain hypothesis, small ants should be better able to walk into environmental interstices. Therefore, we expect smaller ants to be the first ones to reach food in the covered baits and rugose landscapes.

\section{Methods}

This study was conducted in February 2001 and 2002 at La Selva Biological Station of the Organization for Tropical Studies, in the Atlantic lowlands of Costa Rica $\left(\begin{array}{llllll}10^{\circ} & 26^{\prime} & \mathrm{N}, 83^{\circ} & 59^{\prime} & \mathrm{W}\end{array}\right)$. Mature wet-lowland rainforest covers most of the area, with $4000 \mathrm{~mm}$ of average annual precipitation and a relatively drier season from January through April (see McDade et al. 1994 for further information). The canopy, with trees over $30 \mathrm{~m}$ in height, is discontinuous with frequent gaps caused by tree falls. On the forest floor, the accumulation of litter varies largely even at small spatial scales (e.g. $\left.\mathrm{cm}^{2}\right)$.

We conducted two experiments to test how different levels of environmental rugosity and food exposure affect the probability of accessing food by ants with different body sizes. This allows us to elucidate how body size affects ants' ability to explore environments with varying physical heterogeneity. We also examined whether small body size was associated with a greater ability of reaching food in heterogeneous environments across ant species after controlling for the effect of phylogeny, as explained below.

\section{Experiment 1: manipulation of landscape rugosity}

In February 2001, we experimentally tested the ability of ants with different body sizes to discover a food source in 'landscapes' (= plots) with varied rugosity. For this experiment, 32 sites separated at least by $10 \mathrm{~m}$ were randomly selected in an old-growth forest. In each site we established three $50 \times 50 \mathrm{~cm}$ plots in a block design, each plot separated by $10 \mathrm{~cm}$. Leaf litter was removed from each plot, and one of the following treatments randomly assigned to each plot: (a) no leaf litter (plain landscape), (b) $0.5 \mathrm{~kg}(\sim 300 \mathrm{ml})$ of leaf litter (intermediate rugosity), and (c) $1 \mathrm{~kg}(\sim 600 \mathrm{ml})$ of leaf litter (high rugosity). The leaf litter included fallen leaves, twigs, and other small parts of plants obtained from nearby sites and were carefully cleared of ants before used in the experiment. At the center of each plot, a group of food baits was placed "hidden" between two dead leaves. We employed tuna, honey, "gallo pinto" (rice and beans with spices), and fragmented oat flakes as food baits in each plot to attract ant species with different foraging habits. Under the assumption that an increase in the density of litter fall 
increases the number of environmental interstices, these treatments represented different levels of landscape rugosity that may occur in nature. Considering the high ant species richness in tropical forests (Kaspari et al. 2000) and the random distribution of our sample sites within the forest, we assumed that ants with different body sizes had about the same opportunity to arrive at all plots.

\section{Experiment 2: manipulation of food exposure}

To test the ability of ants with different body sizes to discover food with different levels of exposure, we performed a second experiment in February 2002. In this case, nineteen sites were randomly selected in an old-growth forest, separated by approximately $10 \mathrm{~m}$. In each site we placed a block of two $50 \times 50 \mathrm{~cm}$ plots, each plot separated by $10 \mathrm{~cm}$, both cleaned of leaf litter. Two treatments, covered vs. exposed baits, were randomly assigned to each plot. Food baits contained the same items used in the first experiment. In each "exposed food" plot, food baits were located on one dead leaf at the center of the plot. In each "covered food" plot, food baits were located within a pile of dead leaves (approximately 6) at the center of the plot. We assumed that by changing the exposure of food baits (on or among dead leaves), we modified the conditions for ants to access the baits, as may occur in nature.

Because of the short distance among plots within a site, we assume that the finding of baits in the different experimental plots is a good indicator of an ant's ability to explore different topographical features, as in natural conditions. Therefore, in both experiments, we recorded as 'first arrival' the first individual of any ant species that made physical contact with any of the baits within a plot. We captured all these ants that first reached food baits for identification and measuring. The body size of each individual was measured as the total body length (excluding antennae) to the nearest $0.1 \mathrm{~mm}$; we also measured the length of a hind leg to verify the allometric relationship proposed by Kaspari and Weiser (1999).

For the design of the experiments, each plot was used only once. In each year, blocks were monitored simultaneously, half at mid-morning and half at midafternoon. This controls for differences in ant species composition due to changes in daily activity. Nocturnal activity was not included; however, because of our comparative block design, we expect that any changes in species composition between diurnal and nocturnal faunas do not substantially affect our interpretations.

Since the abundance of different ant species may vary among forest sites and such variation may affect the probability that a given ant species first finds a food bait, we examined differences in ant body size among treatments using a one-way, randomized block design analysis of variance. For this analysis, we used rugosity level as the main (fixed) effect and sites as blocks. In the second experiment, paired t-tests were used. Arcsine transformations were used, when needed, to meet the assumptions of normality.

\section{Test of the size-grain hypothesis using a phylogenetic comparative method}

In the two experiments performed we considered differences in the body sizes of ants to make general inferences about their ability to reach food, regardless of whether individuals captured belong to different or the same taxonomic group. However, individuals of closely related species can be more similar in body size than individuals of distantly related species, and may share other characteristics that may be both relevant and irrelevant to the ability of discovering food baits in rugose landscapes, which could potentially complicate interpretation of our results (see Harvey and Pagel 1991, Harvey 1996, for discussion). Thus, we considered species as experimental units and performed a comparative analysis by independent contrasts (CAIC) (Purvis and Rambaut 1994, 1995), which allowed us to control for phylogenetic relatedness while testing our original hypothesis. CAIC allows application of the independent contrast method (Felsenstein 1985, Harvey and Pagel 1991) to phylogenies that are not fully resolved, using Pagel's (1992) method. Using CAIC we tested whether a change toward smaller body size in ants is associated with greater ability to discover food in rugose landscapes in a way that can be interpreted as adaptive.

We classified all the species captured using two alternative phylogenies as working hypotheses for the phylogenetic relationships among sub-families. 'Phylogeny 1' is after Grimaldi et al. (1997), Grimaldi and Agosti (2000), and Baroni-Urbani (2000) and is available at http://tolweb.org/tree?group = Formicidae\&contgroup $=$ Vespoidea, and 'Phylogeny 2' is from Hölldobler and Wilson (1990). We used the taxonomic structure as a rough approximation of phylogenetic relationships below the sub-family level. Comparative data involved mean body size ( $\log _{10}$-transformed) for each species ( $\mathrm{N} \sim 5$ for each species) as the continuous dependent variable, and the type of landscape was the independent descriptor coded as a categorical variable with two states: 1) heterogeneous environment (food baits placed in rugose landscapes or covered by litter fall in plain landscapes), and 2) plain environment (exposed food baits and/or food baits placed in plain landscapes). Each species was assigned to a particular landscape (rugose or plain) if more than $75 \%$ of its sampled individuals first reached food in any of those landscapes. 
CAIC examined the relationship between the dependent and independent variables within each pair of taxa below a node in bi-furcating phylogenies. Given that taxa in each comparison are equally related to each other, the relationship between the variables is unaffected by phylogeny. In the present analysis, only approximate phylogenies were available, thus CAIC calculated a single value ('contrast') for each variable within each taxon (i.e., for species within each genus, sub-family) representing its magnitude and direction of change. Each contrast is usually scaled using information on the length of the branches. Given that in the present analysis no such information was available, all branches were assumed to be of equal length and equal to 2 (Harvey and Pagel 1991, Purvis and Rambaut 1994, 1995).

CAIC settled all the raw contrast in the predictor (=type of landscape) variable as +1 . A negative contrast in the continuous variable $(=(\log )$ body length) means that among the taxa being contrasted, higher values of body size are found in taxa having the dichotomous trait in the lower state (i.e. plain landscape $=0$ ). Under the null hypothesis that the evolution of body size was not associated with a better performance in different types of landscapes, we should expect half the contrasts in body size to be negative and half to be positive. Alternatively, the size-grain hypothesis predicts a bias towards negative scores (see Purvis and Rambaut 1994, 1995 for a more detailed explanation).

\section{Results}

\section{Individual ants as experimental units}

In the two experiments combined we recorded a total of 134 ants of 17 species, 12 genera in 4 sub-families. In the first experiment we captured a total of 96 ants (one per plot, 3 plots per site, 32 sites) and in the second a total of 38 ants (one per plot, two plots per site, 19 sites). The most common species were Aphaenogaster arancoides, Ectatomma tuberculatum, E. ruidum, Acromyrmex volcanus, and unidentified species (i.e. categorized to morphospecies) from the genera Pheidole, Trachymyrmex, Tapinoma, Megalomyrmex, Neostruma, Crematogaster, Solenopsis and Camponotus. For each species, all individual ants we captured belonged to the same caste.

Body length and the hind leg/body length ratio were positively correlated for individuals $(\mathrm{r}=0.95, \mathrm{P}<$ $0.001, \mathrm{n}=134)$ and ant species $(\mathrm{r}=0.84, \mathrm{P}<0.001$, $\mathrm{n}=17)$. These results agreed with those of Kaspari and Weiser (1999) and Espadaler and Gómez (2001) and confirm that small ants have smaller legs than expected by isometry. Therefore, we used body length as our dependent variable since such a variable adequately
Table 1. Total body length (mean $\pm 1 \mathrm{SD}$ ) of individual ants that first arrived to food baits in plots with (a) different level of environmental rugosity (different densities of litter) and (b) different level of bait exposure (covered or uncovered with dead leaves). See text for further explanations. (a) one-way, randomized block design, $\mathrm{F}_{2,61}=11.3, \mathrm{P}<0.05$, (b) paired t-test, $t=2.3$, d.f. $=16, P=0.02$. For each analysis different superscripts means significant statistical differences. (a)

\begin{tabular}{lll}
\hline Rugosity level & $\begin{array}{c}\text { Total body } \\
\text { length (mm) }\end{array}$ & $\begin{array}{l}\text { Ant species } \\
\text { captured }(*)\end{array}$ \\
\hline Low (no litter) & $6.9 \pm 3^{\mathbf{a}}$ & $1,2,3,5,6,9$ \\
Medium (300 g of litter) & $4.1 \pm 2^{\mathbf{b}}$ & $4,7,8,10,11,12$, \\
& & $13,14,15,16,17$ \\
High (600 g of litter) & $4.0 \pm 2^{\mathbf{b}}$ & $4,7,8,10,11,12$, \\
& & $13,14,15,16,17$
\end{tabular}

(b)

Exposure of food bait

\begin{tabular}{lll}
\hline Exposed (on a dead leaf) & $7.2 \pm 3^{\mathrm{a}}$ & $1,2,3,5,6,9$ \\
Non-exposed (between & $4.0 \pm 3^{\mathrm{b}}$ & $4,7,8,10,11,12$, \\
dead leaves) & & $13,14,15,16,17$ \\
\hline
\end{tabular}

Species list in alphabetical order: 1) Acromyrmex volcanus, 2) Aphaenogaster arancoides, 3) Camponotus sp, 4) Crematogaster sp, 5) Ectatomma ruidum, 6) Ectatomma tuberculatum, 7) Megalomyrmex sp, 8) Neostruma sp, 9) Pachycondyla sp, 10) Pheidole sp 1, 11) Pheidole sp 2, 12) Pheidole sp 3, 13) Pheidole sp 4, 14) Solenopsis sp 1, 15) Solenopsis sp 2, 16) Tapinoma sp, 17) Trachymyrmex sp. (*) Only the ant species most frequently captured are shown.

represents the general morphology of ants and may be directly related to their ability to exploit different habitats.

Body length of captured ants ranged from $1.5 \mathrm{~mm}$ to $12 \mathrm{~mm}$. We found evidence that differences in body length were likely to affect ants' ability to locate food baits under different conditions of exposure and landscape rugosity. Individual ants that first got accessed food baits in the most rugose landscapes were $42 \%$ smaller than ants that first reached baits in plain landscapes (experiment $1, \mathrm{~F}_{2,61}=11.3, \mathrm{P}<0.05$, Table 1). Additionally, individual ants that first discovered the covered food baits were $44 \%$ smaller than those that first discovered the exposed baits (experiment 2, $\mathrm{t}=2.3$, d. f. $=16, P=0.02$, Table 1). In general, we observed that larger ant species found baits by walking on the upper surface of the litter, whereas smaller ant species accessed baits from below by walking within the litter.

\section{Ant species as experimental units and comparative analysis by independent contrasts}

An analysis using ant species as independent sample points suggests that species that first discovered food in rugose landscapes have smaller body size than those species that first discovered food in plain landscapes $(3.5 \pm 0.3 \mathrm{~mm}, \mathrm{~N}=11$ versus $10.1 \pm 0.6 \mathrm{~mm}, \mathrm{~N}=6$ respectively, mean $\pm \mathrm{SE}$, Mann-Whitney $U$ Test $=66$, 
$\mathrm{P}=0.0001)$. However, this kind of analysis overestimates the degrees of freedom for statistical tests and so elevates the risk of Type I error (Harvey and Pagel 1991). Nonetheless, the comparative analysis by independent contrasts is consistent with the prediction of the size-grain hypothesis. The analyses using both phylogenies 1 and 2 produced two negative contrasts. The first one $(-0.24)$ is among eight subtaxa below the node leading to the 'Myrmicinae' sub-family, and the second one $(-0.20)$ is between 2 subtaxa below the node leading to the Dolichoderinae, Formicinae and Ponerinae.

\section{Discussion}

The present study offers experimental support to the size-grain hypothesis, confirming that small litter ants are better able to explore environmental interstices in search for food resources than do large ones (Kaspari and Weiser 1999, Espadaler and Gómez 2001). Moreover, our findings also support that the interaction between the spatial distribution of food resource and environmental grain greatly influences the match between resources and consumers (Bell 1990, Ranta et al. 2000).

We found that the ability of ants to discover baits in landscapes with different levels of rugosity and exposure is influenced by their body size. Ants that first discovered baits in the most rugose landscapes, or covered within dead leaves, were $\sim 40 \%$ smaller than ants that first arrived at plain landscapes or exposed baits. There are several reasons to argue that these differences in body size do not emerge merely from a sampling artifact but reflect the differential abilities of ants to explore environmental interstices. First, the proximity of plots within a site strongly reduced the possibility that differences in the body size of ants among treatments were the consequence of the spatial variation in the abundance of ant species. Second, food baits were the same in all treatments, minimizing the possibility for the order of arrival of individuals to reflect the foraging habits of different ant species. Third, the density of leaf litter and the level of food exposure in our experimental plots did not represent a physical barrier for larger ants to access baits. In spite of the fact that large ants less quickly had accessed to food located in narrow interstices, all ant sizes eventually accessed food in both rugose and plain landscapes as well as exposed and covered food baits (see the SD values in Table 1). Moreover, large ants sometimes arrived to the experimental plots first but reached the baits later than small ants. Large ants access to the bait was delayed by the conditions of environmental rugosity in which baits were placed. We occasionally also observed large ants in the rugose landscapes accessing food baits after several minutes of searching; however, in all cases small ants had accessed baits long before. These observations indicate that density of leaf litter and level of food exposure did not physically prevent ants from accessing food. But body length greatly influenced the arrival order of ant species to their resources.

We showed that the efficiency in food resource exploitation by ant species with different body sizes is directly related with the scale of environmental heterogeneity. This suggests that the litterfall of the tropical forest floor may act at least as two different habitats for litter ants: the less rugose exposed upper surfaces of dead leaves where large ant species are more efficient, and the more rugose interstices inside the litter where small ants can exploit food sources available mainly in crevices (Kaspari and Weiser 1999, Yanoviak and Kaspari 2000). The ability to explore environmental interstices, and thus to have access to covered food, may represent a competitive advantage for small ants in environments with a high level of rugosity, as well as possibly reflect their efficiency in exploiting certain environments while reducing potential competition with larger ants. This strategy may be particularly effective when many food items are small and can be removed by the first individual that finds them (exploitative competition, Schoener 1983, Fellers 1987). Small food items are common for tropical litter ants because most species are omnivores, harvesting exudates and debris from plants, scavenging for insects, and capturing prey as encountered (Hölldobler and Wilson 1990, Tobin 1994). Other possible advantages of being able to reach small environmental interstices, such as protection from predators and parasites, and a place to ambush prey (Schatz and Wcislo 1999), deserve further studies.

The present study suggests that differences in the body size of ant species may affect the performance of individuals while foraging in different types of habitats. These effects could scale up to affect the performance of whole colonies as well. Intraspecifically, size-caste differences have been considered key in explaining the economic advantage of a division of labor within colonies (Oster and Wilson 1978); they have been related, for instance, to differences in foraging selectivity (Davidson 1977, Wetterer 1994, 1995, Kaspari 1996). Worker polymorphism allows colonies to collect different-sized resources (Wilson 1980, Kaspari 1996, Willot et al. 2000) and expand the overall period of external activity due to differences in their thermal tolerances, thus enhancing the success of colonies (Kaspari 1996, Cerdá and Retana 1997). Our study further suggests that polymorphic ants may enhance the success of colonies by exploring and foraging in environments with different levels of rugosity. 
The spatial variation in the rugosity of the environment may also affect the spatial distribution of ant species and therefore the structure of ant assemblages. For example, Yanoviak and Kaspari (2000) found that differences in the body size distribution of ant species between canopy and litter habitats were caused by an interaction between organism morphology and environmental characteristics. They interpreted the unimodal body size frequency distribution of ant species found in the canopy as the consequence of ants' movements along branches with few obstacles occurring mainly over a linear dimension of environment. The bi-modal frequency distribution observed in the litter was explained by the coexistence of larger ants that can step over gaps between leaves with smaller ants that can walk through the litter interstices. Therefore, the rugosity level of the environment may act to favor or disfavor divergent ant body sizes (Yanoviak and Kaspari 2000). Additionally, habitat rugosity may affect the interactions of ants with plants and other animals. For example, microsites with different levels of structural complexity on an Ukranian deciduous forest floor differ in the composition of ant species (Gorb and Gorb 1999). Presumably, those microsites also differ in terms of the ants' body sizes frequency distributions. Because larger ant species remove mainly seeds of large-seeded myrmecochores, differences in the abundance of ant species that differ in body size may influence the dispersal of those plants (Kaspari 1996, Gorb and Gorb 1999).

If the scale at which the environmental heterogeneity is perceived by ants operates as a selective force that has shaped the morphological characteristics of a species, this has evolutionary implications. The SGH may be considered as an alternative explanation to the competitive hypothesis for understanding character displacement and ecological packing of species in a community.

Finally, the relationship between body size of species and habitat perception, as verified in the present analysis, also suggests that the definition of habitat for different species would depend on each species' spatial scale of perception (Levin and Pacala 1997, Mech and Zollner 2002). Therefore, to preserve the maximum biodiversity in a particular environment, we must preserve all subsets of "habitats" as perceived by different species. Conservation efforts will depend on our ability to detect patterns at different levels of spatial heterogeneity.

Acknowledgements - Vicky Ortiz, Victor Carmona, Agustina Malizia, Floria Mora, Manuel Morales, Lila Sainz, Katja Poveda, and Pablo Allen assist during fieldwork. We greatly appreciate the assistance of Paul Hanson who identified the ants. Useful comments on several versions of the manuscript were provided by R. Dunn, J. M. "Pajaro" Morales and W. Wcislo. We thank La Selva Biological Station and the Organization for Tropical Studies (OTS) for their logistical support.

\section{References}

Baroni-Urbani, C. 2000. Rediscovery of the Baltic amber ant genus Prionomyrmex (Hymenoptera, Formicidae) and its taxonomic consequences. - Ecol. Geol. Helvetiae 93: 471480 .

Bell, J. W. 1990. Searching behavior. - Chapman and Hall.

Brown, J. 1975. Geographical ecology of deserts rodents. - In: Cody, M. and Diamond, J. M. (eds), Ecology and evolution of communities. Belknap Press, Cambridge, Mass., pp. $315-341$.

Cerdá, X. and Retana, J. 1997. Links between worker polymorphism and thermal biology in a thermophilic ant species. - Oikos 78: 467-474.

Crist, T. and Wiens, J. 1994. Scale effects of vegetation on forager movement and seed harvesting by ants. - Oikos 69: $37-46$.

Davidson, D. 1977. Species diversity and community organization in desert seed-eating ants. - Ecology 58: 711-724.

Espadaler, X. and Gómez, C. 2001. Formicinae ants comply with the size-grain hypothesis. - Funct. Ecol. 15: 136-139.

Fellers, J. 1987. Interference and exploitation in a guild of woodlands ants. - Ecology 68: 1466-1478.

Felsenstein, J. 1985. Phylogenies and the comparative method. - Am. Nat. 125: 1-15.

Gorb, S. and Gorb, E. 1999. Effects of ant species composition on seed removal in deciduous forest in eastern Europe. - Oikos 84: 110-118.

Grimaldi, D. and Agosti, D. 2000. A Formicine in New Jersey Cretaceous amber (Hymenoptera: Formicidae) and early evolution of the ants. - Proc. Natl Acad. Sci. USA 97: 13678-13683.

Grimaldi, D., Agosti, D. and Carpenter, J. M. 1997. New and rediscovered primitive ants (Hymenoptera: Formicidae) in Cretaceous amber from New Jersey, and their phylogenetic relationships. - Am. Mus. Nov. 3208: 1-43.

Gross, J., Zank, C. and Hobbs, N. et al. 1995. Movement rules for herbivores in spatially heterogeneous environments: responses to small-scale pattern. - Landscape Ecol. 10: $209-217$

Harvey, P. H. 1996. Phylogenies for ecologists. - J. Anim Ecol. 65: 255-263.

Harvey, P. H. and Pagel, M. D. 1991. The comparative method in evolutionary biology. - Oxford Univ. Press.

Hölldobler, B. and Wilson, E. O. 1990. The ants. - Belknap Press.

Hutchinson, G. 1959. Homage to Santa Rosalia, or why are there so many kinds of animals? - Am. Nat. 93: 145-159.

Irschick, D. J. and Garland Jr, T. 2001. Integrating function and ecology in studies of adaptations: investigations of locomotor capacity as a model system. - Annu. Rev. Ecol. Syst. 32: $367-396$

Kaspari, M. 1996. Worker size and seed size selection by harvester ants in a Neotropical forest. - Oecologia 105: $397-404$.

Kaspari, M. and Weiser, D. 1999. The size-grain hypothesis and interspecific scaling in ants. - Funct. Ecol. 13: 530538

Kaspari, M., O’Donnell, S. and Kercher, J. R. 2000. Energy, density, and constraints to species richness: ant assemblages along a productivity gradient. - Am. Nat. 155: $280-293$

Levin, S. A. 1992. The problem of pattern and scale in ecology. - Ecology 73: 1943-1967.

Levin, S. and Pacala, S. 1997. Theories of simplification and scaling of spatially distributed processes. - In: Tilman, D. and Kareiva, P. (eds), Spatial ecology: the role of space in population dynamics and interspecific interactions. Princeton Univ. Press, pp. 271-295.

Lindstrom, J., Kaila, L. and Niemela, P. 1994. Polyphagy and adult body size in geometrid moths. - Oecologia 98: $130-132$. 
McDade, L., Bawa, K., Hespeheide, H. et al. 1994. La Selva: ecology and natural history of a tropical rain forest. - Univ. of Chicago Press.

McIntyre, N. and Wiens, J. 1999. How does habitat patch size affect animal movement? An experiment with darkling beetles. - Ecology 80: 2261-2270.

Mech, S. and Zollner, P. 2002. Using body size to predict perceptual range. - Oikos 98: 47-52.

Morales, J. M. 2002. Behavior at habitat boundaries can produce leptokurtic movement distributions. - Am. Nat. 160: $531-538$.

Oster, G. and Wilson, E. O. 1978. Caste and ecology in the social insects. - Princeton Univ. Press.

Pagel, M. D. 1992. A method for the analysis of comparative data. - J. Theor. Biol. 156: 431-442.

Peters, R. 1983. The ecological implications of body size. - Cambridge Univ. Press.

Purvis, A. and Rambaut, A. 1994. Comparative analysis by independent contrasts (CAIC) Version 2. - Oxford Univ. Press.

Purvis, A. and Rambaut, A. 1995. Comparative analysis by independent contrasts (CAIC): an Apple Macintosh application for analyzing comparative data. Computer. - Appl. Biosci. 11: 247-251.

Ranta, E., Lundberg, P. and Kaitala, V. 2000. Size of environmental grain and resource matching. - Oikos 89: 573-576.

Schatz, B. and Wcislo, W. 1999. Ambush predation by the poneriane ant Ectatomma ruidum Roger (Formicidae) on a sweet bee Lasioglossum umbripenne (Halictidae), in Panamá. - J. Insect Behav. 12: 641-663.

Schmidt, K. and Brown, J. S. 1996. Patch assessment in fox squirrels: the role of resource density, patch size, and patch boundaries. - Am. Nat. 147: 360-380.
Schoener, W. 1983. Field experiments on interspecific competition. - Am. Nat. 122: 240-285.

Sparow, A. 1999. A heterogeneity of heterogeneities. - Trends Ecol. Evol. 14: 422-423.

Tobin, J. 1994. Ants as primary consumers: diet and abundance in the Formicidae. - In: Huntand, J. and Napela, C. (eds), Nourishment and evolution in insect societies. Westview Press, Boulder, pp. 278-309.

Wainwright, P. 1996. Ecological explanation through functional morphology: the feeding biology of sunfishes. - Ecology 77: 1336-1343.

Wetterer, J. 1994. Forager polymorphism, size-matching, and load delivery in the leaf-cutting ant, Atta cephalotes. - Oecologia 98: 235-238.

Wetterer, J. 1995. Forager size and ecology of Acromyrmex coronatus and other leaf-cutting ants in Costa Rica. - Oecologia 104: 409-415.

Wiens, J. 1989. Spatial scaling in ecology. - Funct. Ecol. 3: 385-397.

Wiens, J., Schooleyand, R. and Weeks Jr, R. 1997. Patchy landscapes and animal movements: do beetles percolate? - Oikos 78: 257-264.

Willot, S., Comptomand, S. and Incoll, L. 2000. Foraging, food selection and worker size in the seed harvesting ant Messor bouveri. - Oecologia 125: 35-44.

Wilson, E. O. 1980. Caste and division of labor in leaf-cutting ants I. The overall pattern in Atta sexdens. - Behav. Ecol. Sociobiol. 7: 143-156.

Yanoviak, S. and Kaspari, M. 2000. Community structure and the habitat templet: ants in the tropical forest canopy and litter. - Oikos 89: 259-266. 